\title{
Low Antithrombin III Levels in Neonates with Idiopathic Respiratory Distress Syndrome: Poor Prognosis
}

\author{
MARJOLEIN PETERS, ${ }^{(37)}$ JAN W. TEN CATE, CEES BREEDERVELD, RICHARD DE LEEUW, \\ JEF EMEIS, AND JANNA KOPPE \\ Division of Hemostasis and Thrombosis [M.P., J.W.t.C.] and the Departments of Pediatrics [C.B.] and \\ Neonatology [R.d.L., J.K.] Academic Hospital of the University of Amsterdam, Amsterdam and Gaubius Institute \\ [J.E.], Leiden, The Netherlands
}

\section{Summary}

Automated microanalytic chromogenic coagulation assays allow serial monitoring of critically ill newborn infants. In this study 84 premature infants [ 26 healthy prematures and 58 neonates with idiopathic respiratory distress syndrome (IRDS)] were studied daily during the first week of life, to investigate the possible significance of hemostatic abnormalities in IRDS.

In neonates with IRDS, coagulation factors II and $\mathrm{X}$, antithrombin III (AT-III), plasminogen, and $\alpha_{2}$-antiplasmin were significantly lower than control values. Recovery of the initially low AT-III levels was delayed relative to the other coagulation parameters measured. An AT-III $\leq 0.15 \mathrm{U} / \mathrm{ml}$ was present within the first $6 \mathrm{~h}$ of life in eight patients who developed IRDS, seven of whom died within $48 \mathrm{~h}$. Autopsy of these neonates showed widespread fibrin deposition and hemorrhage in vital organs consistent with intravascular coagulation. These findings indicate that very low levels of AT-III are associated with disseminated intravascular coagulation in neonates with IRDS and suggest that a deficiency of AT-III is predictive of a poor outcome.

\section{Abbreviations}

AT-III, antithrombin III

DIC, disseminated intravascular coagulation

IRDS, idiopathic respiratory distress syndrome

IVH, intraventricular hemorrhage

DIC is frequently encountered in premature newborn infants suffering from IRDS. Deficiencies in clotting factors and fibrinogen, increased levels of fibrinogen/fibrin degradation products and thrombocytopenia $(2,4,19,22,23)$ have been reported to be caused by DIC. These coagulation abnormalities are associated with clinical symptoms of bleeding $(7,8,16,25,29)$ particularly IVH and fibrin thrombi at autopsy $(3,7,16,31)$ suggesting that DIC contributes to the fatal outcome of this disease. Decreased levels of AT-III have been described in early stages of DIC in adult patients $(6,26)$. In cord blood samples of premature infants who developed IRDS, reduced AT-III levels have been reported $(18,21,34)$; however, the relationship between AT-III activity and the clinical course of IRDS has not yet been thoroughly investigated. The availability of automated chromogenic coagulation assays enables the serial study of several coagulation parameters, and of AT-III in particular, in premature neonates with IRDS. These results are correlated with clinical signs and autopsy findings.

\section{SUBJECTS AND METHODS}

Subjects. The study group included 84 premature infants admitted to the neonatal intensive care unit of our hospital during the year 1981. Estimation of gestational age was based upon maternal dates and the Dubowitz scoring method (10). All neonates received vitamin $\mathrm{K}_{1}(0.5-1.0 \mathrm{mg}$ ) (Konakion, HoffmanLa Roche, Basel, Switzerland) intramuscularly upon delivery. Newborn infants were subdivided into two groups (Table 1). Classification was made according to examination by a neonatologist (R. de Leeuw), who was unaware of the patient's coagulation profile. Control patients included 26 premature newborn infants who were in stable clinical condition. Birth weights were appropriate for gestational age. These infants served as a control group for those infants surviving IRDS. Birth weight and gestational age did not differ significantly (Table 1). Patients with IRDS ( $n=58$ ) fulfilled the following criteria: 1) symptoms of respiratory distress (Silverman score $>3$ ) within $1 \mathrm{~h}$ after birth and present for at least $24 \mathrm{~h}$; 2) reticulogranular pattern with airbronchograms on chest $\mathrm{x}$-ray; and 3) evidence of right to left shunting determined by transcutaneous $\mathrm{PO}_{2}$ determinaton and capillary blood gas analysis. Respiratory support included mechanical ventilation through endotracheal intubation followed by continuous positive air pressure $(n=33)$, or continuous positive air pressure only $(n=25)$. The duration of ventilatory support was greater than $7 \mathrm{~d}$ in 16 neonates, all of whom developed bronchopulmonary dysplasia. A standard postmortem examination of all organs was performed in infants who died within $48 \mathrm{~h}$ after birth. Histologic examinations were performed according to standard techniques including hematoxilin and eosin staining. Fibrin-related antigens were demonstrated using an indirect immunoperoxidase technique with affinity-purified antihuman fibrinogen $\operatorname{IgG}(11)$.

Sampling and methods. Blood samples were obtained from the umbilical or peripheral veins, or by heel puncture (24). The initial blood sample was obtained within $6 \mathrm{~h}$ after birth and subsequent samples were taken daily.

Blood $(0.3 \mathrm{ml})$ was collected into polypropylene tubes (Greiner, Nürtingen, Germany) containing solid $\mathrm{K}_{2}$ EDTA $(1.5 \mathrm{mg} /$ $\mathrm{ml})$. Plasma was prepared by centrifugation at $13,000 \mathrm{~g}$ for 4 min at room temperature. Automated chromogenic determinations of AT-III (20), factor X (29), factor II (24), plasminogen (24), and $\alpha_{2}$-antiplasmin (24) could be performed with $70 \mu \mathrm{l}$ of plasma. Normal adult and healthy term neonate values of these assays are $0.80-1.40 \mathrm{U} / \mathrm{ml}$ and $0.40-0.80 \mathrm{U} / \mathrm{ml}$, respectively. Platelet counts were performed according to Feissly and Lüdin (12). Thrombocytopenia was defined as a platelet count below $100 \times 10^{9} / 1(13)$. 
Table 1. Means of birth wt and gestational age in the control group and both iodiopathic respiratory distress syndrome (IRDS) subgroups, ranges given in parentheses

\begin{tabular}{lcc}
\hline & & $\begin{array}{c}\text { Gestational } \\
\text { age } \\
(\mathrm{wk})\end{array}$ \\
\hline Control group $(n=26)$ & Birth wt $(\mathrm{g})$ & 31.9 \\
& 1740 & $(29-34)$ \\
IRDS group $(n=58)$ & $(1220-2270)$ & \\
IRDS who died $(n=17)$ & 1035 & 28.6 \\
& $(635-1945)$ & $(26-33)$ \\
IRDS who survived $(n=41)$ & $1625^{*}$ & $30.8^{*}$ \\
& $(810-2530)$ & $(26-34)$ \\
\hline
\end{tabular}

* No statistically significant difference in comparison to the control group.

Statistical methods. Statistical evaluation of the data was performed using the one-way analysis of variance and Student's $t$ test.

\section{RESULTS}

Coagulation investigations. The serial coagulation results in the control and IRDS groups who survived are shown in Figure 1. In the control group the mean plasma levels of factors II and $\mathrm{X}, \mathrm{AT}-\mathrm{III}$, and plasminogen varied between 0.3 and $0.5 \mathrm{U} / \mathrm{ml}$. In contrast, the $\alpha_{2}$-antiplasmin concentration was close to the adult range. In all but one of the healthy prematures, the first day AT-III level was over $0.20 \mathrm{U} / \mathrm{ml}$. The AT-III level of that particular infant normalized on the second day. During the first week, AT-III and factor II levels increased significantly. The mean plasminogen and $\alpha_{2}$-antiplasmin levels did not change during the entire study period. Despite vitamin $\mathrm{K}_{1}$ administration, factor $\mathrm{X}$ declined significantly to a minimum on $\mathrm{d} 6(P<$ 0.001 ) for reasons not understood.

In both IRDS subgroups all initial coagulation parameters were significantly lower as compared with the control group $(P$ $<0.001)$. The mean initial AT-III level of the neonates who died was $0.16 \mathrm{U} / \mathrm{ml}$ which was significantly lower as compared with the IRDS group which did survive $(0.21 \mathrm{U} / \mathrm{ml}, P<0.01)$. Seven of the eight neonates with IRDS and an initial AT-III level of less than $0.16 \mathrm{U} / \mathrm{ml}$ died. The mean plasma levels in the surviving IRDS group reached control values at different time intervals (Fig. 1). Factor $\mathrm{X}$ and $\alpha_{2}$-antiplasmin reached control levels after $24 \mathrm{~h}$ whereas factor II and plasminogen were within the normal range on $\mathrm{d} 3$ and 4 , respectively. AT-III levels remained significantly lower until d 5 . Fourteen neonates in the IRDS group (seven survivors, seven non-survivors) developed thrombocytopenia within the first $3 \mathrm{~d}$ and none of the control infants were thrombocytopenic.

Clinical signs of bleeding. A hemorrhagic tendency was present in 17 of 41 neonates surviving IRDS and in all neonates who subsequently died due to IRDS. Bleeding symptoms included skin hematomas, oozing from the umbilical cord or venipuncture sites, gastrointestinal bleeding, and IVH, diagnosed either clinically or by echography. No signs of bleeding were present in the control group.

Necropsy findings. Twelve neonates developing IRDS died within $48 \mathrm{~h}$ of birth and five died between the third and the sixteenth day. The necropsy findings in 10 newborns, who died within $48 \mathrm{~h}$, and for whom autopsy permission was obtained, are summarized in Table 2. The clinical diagnosis of IRDS was confirmed by the presence of hyaline membranes (using routine staining procedures) in all cases.

In seven cases, fibrin deposition was observed within the hyaline membranes (Fig. 2). In eight neonates, fibrin thrombi were diffusely present in the microcirculation of the kidneys, liver, or lungs. The clinical diagnosis of IVH was confirmed in six neonates. In all neonates some form of cerebral hemorrhagic
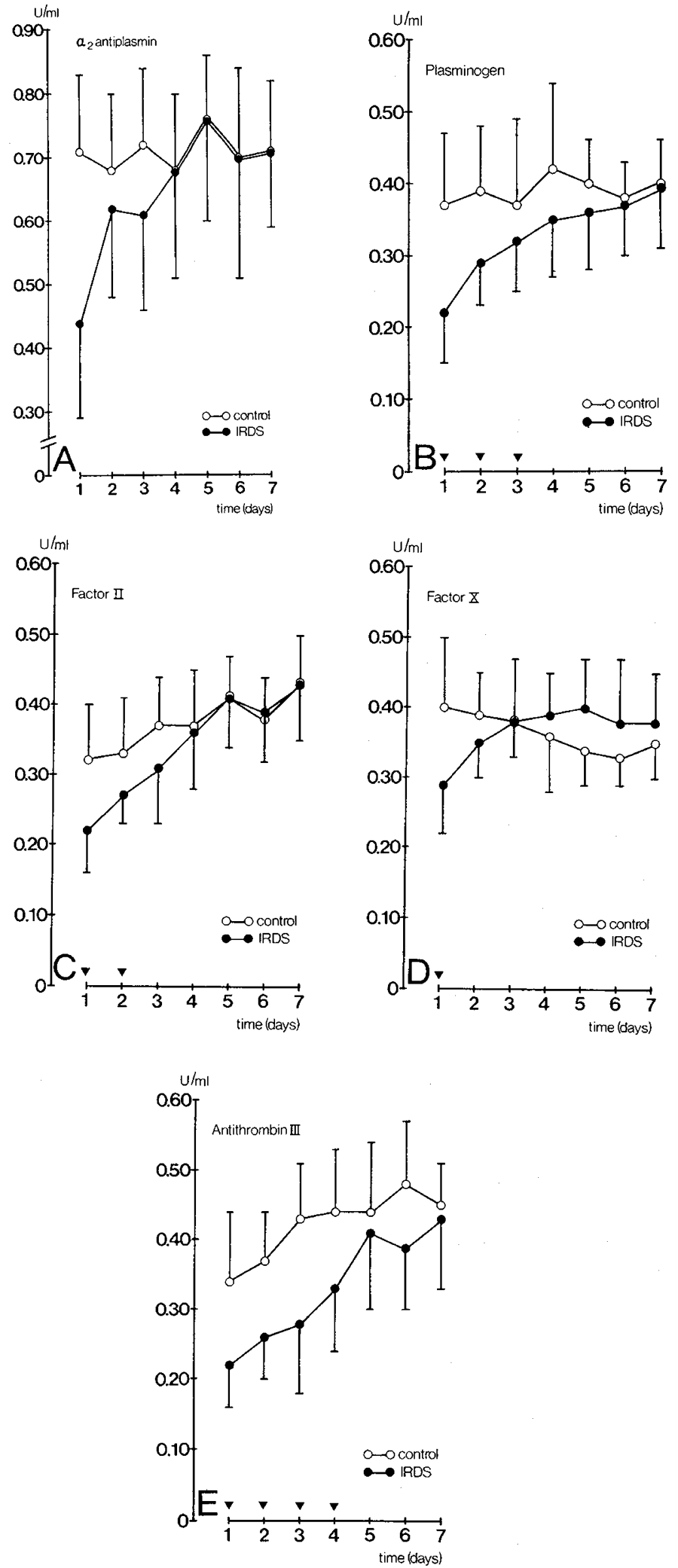

Fig. 1. Profile of the coagulation and fibrinolytic parameters, during the first week of life in healthy neonates (-O-), neonates with idiopathic respiratory distress syndrome (IRDS) who survived (--) (mean + SD for controls, mean - SD for IRDS). The days at which statistically significantly different values between healthy neonates and those with IRDS are noted have been marked with $\boldsymbol{\nabla}$.

diathesis was present, including meningeal petechiae, subarachnoidal hemorrhage or IVH. In addition, hemorrhage in the lungs, kidneys and adrenal glands was present in four cases. 
Table 2. Necropsy findings in neonates with IRDS who died within $48 \mathrm{~h}$ after birth

\begin{tabular}{|c|c|c|c|c|c|c|}
\hline \multirow[b]{2}{*}{ No. } & \multirow{2}{*}{$\begin{array}{c}\text { Birth } \\
\text { wt } \\
(\mathrm{g})\end{array}$} & \multirow{2}{*}{$\begin{array}{c}\text { Gestational } \\
\text { age } \\
\text { (wk) }\end{array}$} & \multicolumn{2}{|c|}{ AT-III $\mathrm{U} / \mathrm{ml}$} & \multirow{2}{*}{$\begin{array}{l}\text { Fibrin deposition } \\
\text { and thrombi }\end{array}$} & \multirow[b]{2}{*}{ Hemorrhage } \\
\hline & & & d 1 & $\mathrm{~d} 2$ & & \\
\hline 1 & 1240 & 27 & $0.14^{*}$ & $\ldots$ & liver & cerebral petechiae \\
\hline 2 & 1170 & 27 & $0.04^{*}$ & $\ldots$ & hyaline membrane, liver & IVH, subarachnoid hemorrhage \\
\hline 3 & 1200 & 28 & $0.16^{*}$ & $\ldots$ & liver & cerebral petechiae \\
\hline 4 & 1140 & 31 & $0.03^{*}$ & $\ldots$ & hyaline membrane, liver & cerebral petechiae \\
\hline 5 & 1120 & 28 & $0.15^{*}$ & $\ldots$ & hyaline membrane, liver & IVH \\
\hline 6 & 1200 & 30 & 0.12 & $0.24 *$ & hyaline membrane, liver kidneys & $\begin{array}{l}\text { cerebral petechiae, IVH, kid- } \\
\text { neys }\end{array}$ \\
\hline 7 & 1200 & 32 & 0.10 & $0.22 *$ & lungs, kidneys & IVH, adrenal glands, kidneys \\
\hline 8 & 635 & 27 & $0.12^{*}$ & & hyaline membrane & cerebral petechiae, IVH, lungs \\
\hline 9 & 840 & 31 & $\ldots$ & $0.28^{*}$ & hyaline membrane & cerebral petechiae, IVH, lungs \\
\hline 10 & 1010 & 32 & $0.19^{*}$ & $\ldots$ & hyaline membrane & cerebral petechiae \\
\hline
\end{tabular}

* Deceased.

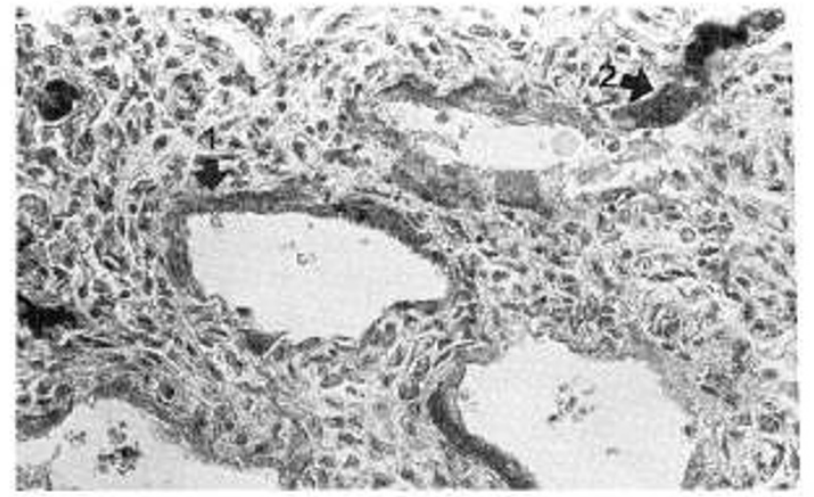

Fig. 2. Fibrin deposition in hyaline membranes $(\rightarrow 1)$ and fibrin thrombi in the microcirculation $(\rightarrow 2)$ of a premature infant who died due to idiopathic respiratory distress syndrome.

\section{DISCUSSION}

In this comprehensive study, severe coagulation abnormalities were demonstrated in premature infants suffering IRDS. Marked deficiencies of coagulation factors II and X and of plasminogen, as well as of the inhibitors of coagulation (AT-III) and fibrinolytic systems ( $\alpha_{2}$-antiplasmin) were observed and were associated with hemorrhage and fibrin thrombi in vital organs at autopsy.

IRDS was defined using a combination of clinical criteria, chest $\mathrm{x}$-ray interpretation, and laboratory parameters in 58 premature newborn infants. Autopsy of 10 newborns who died within $48 \mathrm{~h}$ after birth revealed cerebral hemorrhage in all whereas diffuse hemorrhages in vital organs was noted in four cases. Fibrin thrombi, as visualized by specific antiserum staining, in lungs, liver, kidneys, or fibrin deposition in the hyaline membranes were observed in all cases. Considering these histologic findings, DIC obviously contributed to the fatal clinical course. It was, therefore, of particular interest to find very low AT-III levels in these infants as compared with the survivors. AT-III was the only parameter which distinguished between survivors and non-survivors in the IRDS group.

This severe AT-III deficiency, also observed in cord blood of such infants by other authors $(18,21,34)$, may be the result of both increased turnover in the course of DIC and decreased synthesis due to liver damage. An acquired AT-III deficiency state may, in turn, accelerate the process of DIC and fibrin deposition in the microcirculation. The observed low plasminogen and $\alpha$-antiplasmin levels may be suggestive of reactive fibrinolysis. This is in accordance with the findings of other authors $(2,4,19,22,33)$. The coagulation changes and thrombocytopenia noted are compatible with the observed bleeding tendencies. The high incidence of IVH has also been asociated with coagulation changes (28) although other etiologies are also suggested, i.e., inconsistency of blood pressure, loss of cerebral autoregulation, vascular immaturity, and changes in cardiac output $(9,31)$. Several therapeutic regimens have been investigated in an attempt to decrease mortality and to combat coagulation disorders in IRDS infants. Prophylactic heparin treatment was not successful $(14,23)$ and a definite heparin resistance has been observed $(18,23)$. The failure of heparin treatment in these infants might be ascribed to an AT-III deficiency, as the efficacy of heparin is mainly dependent on this inhibitor. Substitution of plasma alone has also been found to be ineffective (15) as was treatment with plasminogen concentrates (1). As AT-III is the most important physiologic inhibitor of blood coagulation and as the AT-III deficiencies are quite pronounced, it is anticipated that human AT-III concentrates, which were effective in previous clinical studies in adults $(5,27,28)$, may be effective in the prevention or treatment of DIC associated with IRDS. We are currently involved in a double blind randomized study, comparing AT-III concentrates with placebo administration in these premature newborn infants.

\section{REFERENCES AND NOTES}

1. Ambrus, C. A., Weintraub, D. H., Choi, Th.S., Eisenberg, B., Staub, H.P., Courey, N. G., Foote, R. J., Goplerud, D., Moesch, R. V., Ray, M., Bross, I. D. J., Jung, O. S., Mink, I. B. and Ambrus, J. L.: Plasminogen in the prevention of hyaline membrane disease. Am. J. Dis. Child., 127: 189 (1974).

2. Barnard, D. R., Simmons, M. A., and Hathaway, W. E.: Coagulation studies in extremely premature infants. Pediatr. Res., 13: 1330 (1979).

3. Boyd, J. F.: Disseminated fibrin thromboembolism among neonates dying within 48 hrs after birth. Arch. Dis. Child., 42: 401 (1967).

4. Boyer, C., Ménaché, D., Beaufils, F., and Mathieu, H.: Haemostatic disorders and respiratory distress in the newborn. Inten. Care Med., 3: 273 (1977).

5. Büller, H. R. Weenink, A. H. Treffers, P. E., Kahlé, L. H., Otten, H. A., and Ten Cate, J. W.: Severe antithrombin III deficiency in a patient with preeclampsia. Observations on the effect of human AT-III concentrate transfusions. Scand. J. Hematol., 25: 81 (1980).

6. Büller, H. R Thomas, L. L. M. Sturk, A., Roos, J., and Ten Cate, J. W Postoperative behaviour of antithrombin III and plasminogen in relation to gram-negative septicemia and endotoxemia. Submitted.

7. Chessels, J. M. and Wigglesworth, J. S.: Secondary haemorrhagic disease of the newborn. Arch. Dis. Child., 45: 539 (1970).

8. Chessels, J. M. and Wigglesworth, J. S.: Coagulation studies in premature infants with Respiratory Distress and intracranial hemorrhage. Arch. Dis. Child., 47: 564 (1972).

9. Cole, V. A., Durbin, G. M., Olaffson, A., Reynolds, E. O. R., Rivers, R. P. A. and Smith, J. F.: Pathogenesis of intraventricular hemorrhage in newborn infants. Arch. Dis. Child., 49: 722 (1974).

10. Dubowitz, L. M., Dubowitz, V., and Goldberg, C.: Clinical assessment of gestational age in the newborn infant. J. Pediatr., $1: 77$ (1970).

11. Emeis, J. J. Lindeman, J., and Nieuwenhuizen, W.: Immunoenzyme histochemical localization of fibrin degradation products in tissues. Am. J. Path., 103: 337 (1981).

12. Feissly, R. and Lüdin, H.: Microscopie par contrastes de phases (III. Application á l'hématologie). Rev. Hem., 4: 481 (1949).

13. Forfar, J. O. and Arneil, G. N.: Textbook of Pediatrics. p. 177 (Churchill/ Livingstone, Edinburg, 1978).

14. Gobel, U., v. Voss, H., Jürgens, H., Petrich, C., Pothmann, R., Sprock, I., and 
Lemburg, P.: Efficiency of heparin in the treatment of newborn infants with respiratory distress syndrome and disseminated intravascular coagulation. Eur. J. Pediatr., 47: 133 (1980).

15. Hambleton, G. and Aplleyard, W. J.: Controlled trial of fresh frozen plasma in asphyxiated low birth weight infants. Arch. Dis. Child., 48: 31 (1973).

16. Harrison, V. C., de Heese, V., and Klein, M.: Intracranial hemorrhage associated with hyaline membrane disease. Arch. Dis. Child., 43: 116 (1968).

17. Hathaway, W. E., Müll, M. M., and Pechet, G. S.: Disseminated intravascular coagulation in the newborn. Pediatrics, 43: 233 (1969).

18. Hathaway, W. E., Mahasandana, Ch., and Makowski, E. L.: Cord blood coagulation in infants of high risk pregnant women. Am. J. Obstet. Gynaecol., 51: 121 (1974).

19. Hurlet-Birk Jensen, A., Josso, F., Zamet, P., Monset-Chouchard, M., and Minkowski, A.: Evolution of blood clotting factor levels in premature infants during the first 10 days of life: A study of 96 cases with comparison between clinical status and blood clotting factor levels. Pediatr. Res., 7: 638 (1973).

20. Kahlé, L. H., Schipper, H. G., Jenkins, C. S. P., and Ten Cate, J. W.: Antithrombin III. I. Evaluation of an automated antithrombin III method. Thromb. Res., 12: 1003 (1978)

21. Mahasandana, Ch. and Hathaway, W. E.: Circulating anticoagulants in the newborn: Relation to hypercoagulability and the Idiopathic Respiratory Distress Syndrome. Pediatr. Res., 7: 670 (1973).

22. Markarian, M., Githens, J. H., Rosenblüt, E., Fernandez, F., Jackson, J., Bannon, A. E., Lindley, A., Lubchenco, L. O., and Martorell, R.: Hypercoagulability in premature infants with special reference to the Respiratory Distress Syndrome and Hemorrhage 1. coagulation studies. Biol. Neon., 17: 84 (1971)

23. Markarian, M., Lubchenco, L. O., Rosenblüt, E., Fernandez, F., Lang, D., Jackson, J. J., Bannon, A. E., Lindley, A., Githens, J. H., and Martorell, R: Hypercoagulability in premature infants with special reference to the respiratory distress syndrome and hemorrhage. II. The effect of heparin. Biol. Neonate, 17: 98 (1971)

24. Peters, M., Breederveld, C., Kahlé, L. H., and Ten Cate, J. W.: Rapid microanalysis of coagulation parameters by automated chromogenic substrated methods-application in neonatal patients. Thromb. Res., 28: 773 (1982).

25. Prociany, R. S., Garcia-Prats, J. A., Adams, J. M., Silvers, A., and Rudolph, A. J.: Hyaline membrane disease and intraventricular hemorrhage in small for gestational age infants. Arch. Dis. Child., 55: 502 (1980).

26. Schipper, H. G., Roos, J., van der Meulen, F, and Ten Cate, J. W : Antithrombin III deficiency in surgical intensive care patients. Thromb. Res., 73: 73 (1981).

27. Schipper, H. G., Kahlé, L. H., Jenkins, C. S. P., and Ten Cate, J. W.: Antithrombin III transfusion in disseminated intravascular coagulation. Lancet, 2: 854 (1978)

28. Schipper, H. G. and Ten Cate, J. W.: Antithrombin III transfusion in patients with liver cirrhosis. Brit. J. Haematol., 52: 25 (1982).

29. Setzer, E. S., Webb, J. B., Wassenaar, J. W., Reeder, J. D., Metha, P. S., and Eitzman, D. V.: Platelet dysfunction and coagulopathy in intraventricular hemorrhage in the premature infant. J. Pediatr., 100: 599 (1982).

30. Van Wijk, E. M., Kahlé, L. H., and Ten Cate, J. W.: The automted amidolytic techniques for the determination of factor $\mathrm{X}$ and factor $\mathrm{X}$ antigen: application to patients. Clin. Chem., 1:885 (1980).

31. Volpe, J. J.: Neonatal intraventricular hemorrhage. N. Eng. J. Med., 304: 886 (1981).

32. Wade-Evans, T.: Thrombin in the hepatic sinusoids of the neborn and their relation to pulmonary hyaline membrane formation. Arch. Dis. Child., 35: $286(1960)$.

33. Watkins, M. N., Swan, S., Caprini, J. A., Gardner, Th. H., Zuckerman, L., and Vagher, P.: Coagulation changes in the newborn with respiratory failure. Thromb. Res., 17: 153 (1980).

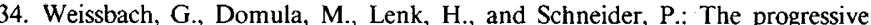
antithrombin activity and its relation to other factors of the coagulation system in newborns. Acta. Pediatr. Scand., 67: 555 (1974).

35. This study was approved by the Committee of Ethics of the Academic Hospital, University of Amsterdam.

36. The authors are grateful to Prof. W. E. Hathaway and Dr. M. M. McDonald for critically reviewing this manuscript and to Dr. J. Bovill for statistical advices. This investigation was supported by grants from the Astma Foundation Nr. 32.80.21 and Foundtion "De Drie Lichten."

37. Requests for reprints should be addressed to: Dr. M. Peters, Division of Hemostasis and Thrombosis, Academic Medical Centre, Meibergdreef 9 , 1105 A2 Amsterdam, The Netherlands.

38. Received for publication February 21, 1983.

39. Accepted for publication September 8, 1983.

\title{
Glucose Turnover Rates in Chronically Catheterized Non-Pregnant and Pregnant Rabbits
}

\author{
WILLIAM W. HAY, JR., ${ }^{(16,18)}$ MARC GILBERT, ROBERT L. JOHNSON, ${ }^{(17)}$ AND \\ FREDERICK C. BATTAGLIA \\ Division of Perinatal Medicine, Departments of Pediatrics and Obstetrics/Gynecology, University of Colorado \\ School of Medicine, Denver, Colorado, USA
}

\section{Summary}

Glucose turnover rates have been measured in conscious, chronically catheterized, non-pregnant and pregnant rabbits. Non-pregnant rabbits were studied weekly for 4 wk. Pregnant animals were studied once while non-pregnant and then weekly for up to 4 wk during pregnancy. Glucose turnover rate was measured using a primed-constant infusion of $\left[\mathrm{U}-{ }^{14} \mathrm{C}\right]$ glucose and $\left[6-{ }^{3} \mathrm{H}\right]$ glucose.

The weight of the rabbits did not vary throughout the 4-5 wk of study in either the non-pregnant or pregnant group. Seven pregnant rabbits delivered pups which weighed an average of 61 g each.

In non-pregnant rabbits, blood glucose concentration did not vary with time. In the pregnant rabbits, blood glucose concentration fell by the end of gestation to an average value of $74.6 \pm 2.7$ $\mathrm{mg} / \mathrm{dl}$, significantly less $(P<0.01)$ than the glucose concentration in the same animals before pregnancy, $88.2 \pm 2.4 \mathrm{mg} / \mathrm{dl}$.

The weight specific glucose turnover rate did not vary with time in either the non-pregnant $\left(4.38 \pm 0.16 \mathrm{mg} \cdot \mathrm{min}^{-1} \cdot \mathrm{kg}^{-1}\right)$ or pregnant rabbits $\left(3.89 \pm 0.29 \mathrm{mg} \cdot \mathrm{min}^{-1} \cdot \mathrm{kg}^{-1}\right)$. Blood glucose clearance did not change over time in the non-pregnant rabbits but did increase in the pregnant rabbits in late pregnancy. Blood glucose clearance was inversely related to the fall in blood glucose concentration.

Glucose turnover rates have been measured during late pregnancy in sheep, guinea pigs, rats, and women. In sheep, weightspecific glucose turnover rates for twin-pregnant ewes have been reported to average nearly $30 \%$ higher than for non-pregnant ewes (2). In pregnant guinea pigs studied over the last half of 